\title{
Relationships between vegetation and soil and topography in a dry warm river valley, SW China
}

\author{
Xian-Li Xu ${ }^{\text {a }}$, Ke-Ming Ma ${ }^{\text {a,* }}$, Bo-Jie Fu ${ }^{\text {a }}$, Cheng-Jun Song ${ }^{\text {a }}$, Wen Liu ${ }^{b}$ \\ a State Key Laboratory of Urban and Regional Ecology, Research Center for Eco-Environmental Sciences, Chinese Academy of Sciences, Beijing 100085, PR China \\ b School of Information Science and Technology, Beijing Institute of Technology, Beijing 100081, PR China
}

\section{A R T I C L E I N F O}

\section{Article history:}

Received 1 January 2008

Received in revised form 29 April 2008

Accepted 29 April 2008

\section{Keywords:}

Arid valley environments

Ecosystem restoration

Multivariate statistical analysis

Vegetation-soil-topography

\begin{abstract}
A B S T R A C T
Understanding of the relationships between vegetation and soil and topography would be very important for ecosystem restoration and management efforts in the dry valleys of Himalayan region but how to clarify the complicated relationships and figure out key factors for practical purpose is a challenge. The main objective of this research was to propose a four-staged procedure by combining several multivariate statistical techniques to detect the relationships between vegetation and soil and topography, and thereby identify the key factors for the degraded ecosystem restoration and management. Forty-three plots $(5 \mathrm{~m} \times 5 \mathrm{~m})$ were selected for the field survey of the vegetation, soil and topography variables in the dry warm river valley of the upper Minjiang River, Sichuan Province, China. Cluster analysis (CA) demonstrated that high plant diversity, cover and height were associated with good soil quality and favorable topographic positions with lower solar incident radiation, runoff and soil erosion potential. Correlation analysis (simple correlation analysis and canonical correlation analysis) and multiple linear stepwise regression analysis affirmed that plant diversity was mainly correlated with soil water content, and soil water content was mainly determined by soil texture (clay content). Soil clay content alone could explain about $70 \%$ of the total variance. Identifying the favorable topographic position and the distribution pattern of soil texture and its controlling mechanisms is thus very important for restoration practices. In the process of ecosystem restoration, we should promote the co-evolution of vegetation and soil, and follow the natural succession sequence. Some relevant conservation polices are also needed to reduce human disturbance on ecosystem.
\end{abstract}

(c) 2008 Elsevier B.V. All rights reserved.

\section{Introduction}

The presence of typical dry valleys in the Himalayan ranges is a unique feature (Schweinfurth, 1992; Wangda and Ohsawa, 2006a,b). These typical dry valleys are distributed from Kabul in the west to Yangtze River in the east running perpendicular to the prevailing mountain ranges, cutting through north to south (Wangda and Ohsawa, 2006a). The strong valley wind that ascends every afternoon together with high temperature during the day increases evapotranspiration at the valley bottom leading to specific local dryness, which is called foehn effects. Major human settlements are located around the bottoms of these dry valleys, local inhabitants often use the nearby forest for timber production, litter for firewood, and many sites are also used often for grazing. Under the combined impacts of both special climatic conditions and intensive human activities, the ecosystems in such dry valley landscapes are degraded greatly, and need effective restoration and management urgently.

The dry valley of upper reach of Minjiang River is mainly distributed in the elevation range from 1200 to $2200 \mathrm{~m}$ with the length of

\footnotetext{
* Corresponding author. Tel./fax: +86 1062849104.

E-mail addresses: xuxianliww@gmail.com (X.-L. Xu), mkm@rcees.ac.cn (K.-M. Ma).
}

about $161 \mathrm{~km}$ and the area of about $170 \mathrm{~km}^{2}$ (Figs. 1 and 2). Vegetation damage along the upper Minjiang River has taken place for at least a thousand years (Yan et al., 2006), and serious soil erosion has occurred, degrading soil water and nutrient conditions (Ma et al., 2004). In an effort to reduce the extent and magnitude of soil erosion, this area has become the key region for ecological rebuilding under the National Eco-environmental Renovating Scheme of China (Li et al., 2006a). Many restoration-related studies have been conducted in this area. Ma et al. (2004) examined the multiple-scale soil moisture distribution and its impacting factors; Li et al. (2005) and Li et al. (2006b) examined the physiological characteristics of some shrub species and their relation to environmental factors; Lu et al. (2006) studied the differential responses of shrubs and herbs to soil variables; Zhou et al. (2008) investigated the relationship between vegetation types and soil orders. However, little research was on the comprehensive analysis of the vegetation-soil-topography relationship, which has been an important subject of ecological and geographic studies, and can provide valuable information for such kind of degraded areas to have successful strategies in restoration and management. Also, this mountainous area with a complicated relief facilitates studying the vegetation-soil-topography relationship (Solon et al. 2007). In order to discern the complex relationships between 


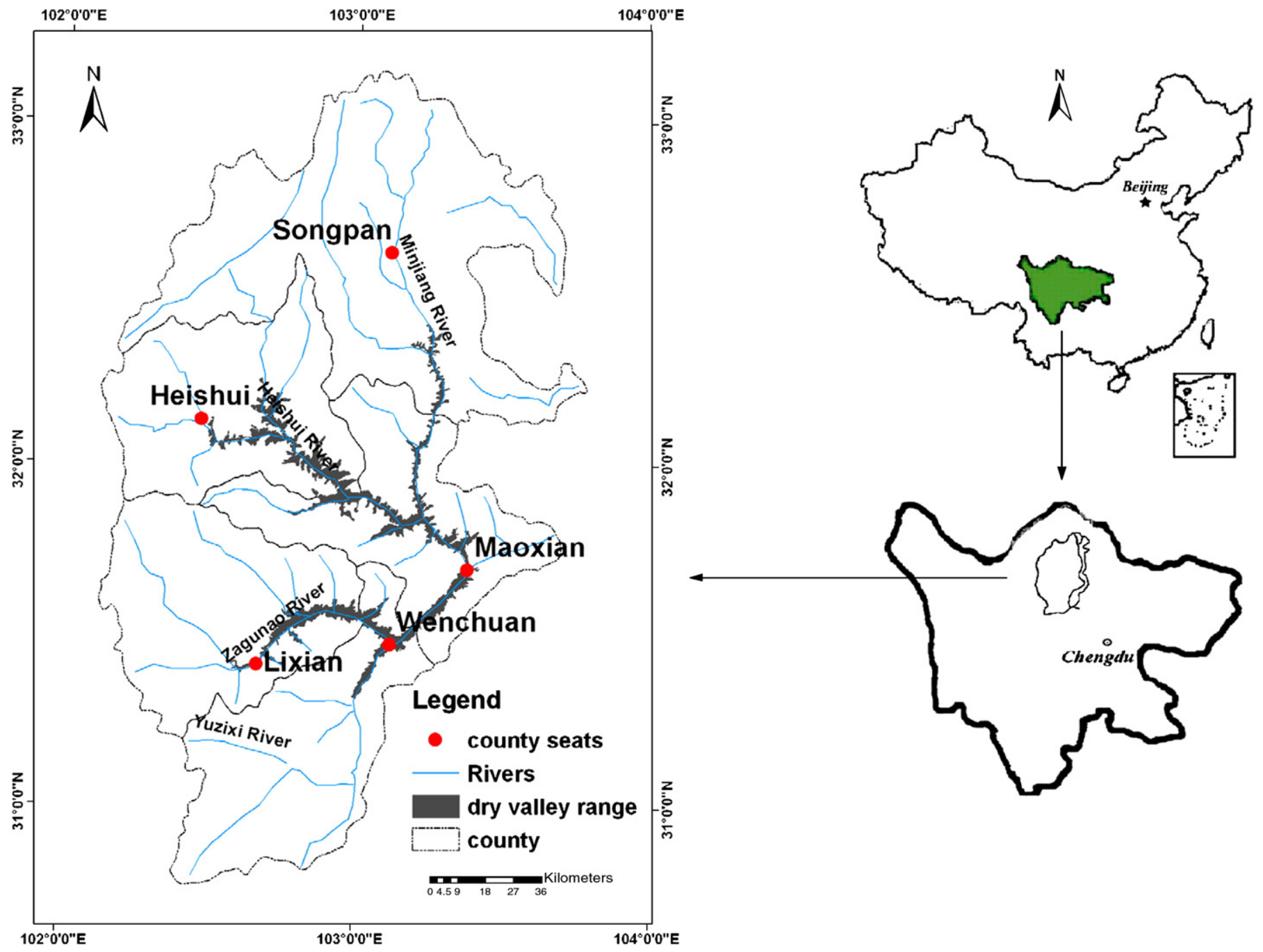

Fig. 1. Location map of Upper Minjiang River Basin and dry river valley.

vegetation and soil and topography, the combination of several multivariate statistical techniques, such as cluster analysis (CA), principal component analysis (PCA), canonical correlation analysis (CCA) and regression analysis, is required (Fu et al., 2004).

This study thus aimed 1) to propose a four-staged procedure by combining several multivariate statistical approaches to detect the relationships between vegetation and soil and topography in a unique dry river valley landscape with a complicated relief, and 2) to find out the implications of the results from this study for arid ecosystem restoration and management. All information got from and the procedure proposed in this study would be very useful not only for our study area but also for other dry valley landscapes in Himalayan ranges and even other arid environments.

\section{Materials and methods}

\subsection{Study area}

The Minjiang River is a first-order branch of the Yangtze River, which is about $735 \mathrm{~km}$ in length and has an altitude range of $3560 \mathrm{~m}$. The upper Minjiang River Basin $\left(30^{\circ} 44^{\prime}-32^{\circ} 24^{\prime} \mathrm{N} ; 102^{\circ} 41^{\prime}-103^{\circ} 58^{\prime} \mathrm{E}\right)$ is a $337 \mathrm{~km}$ section between the headwaters and Dujiangyan City (Fig. 1). The Basin is located in the northwestern corner of Sichuan Province, a transition zone from the Qinghai-Tibetan Plateau to the Sichuan Basin. In the upper Minjiang River basin, maximum elevation is $>3600 \mathrm{~m}$ in the headwaters and the minimum elevation is $<900 \mathrm{~m}$ in Dujiangyan City. The mountainous topography has a large degree of vertical variation in precipitation and air temperature. The dry valley under study is located between 1200 and $2200 \mathrm{~m}$ in a semi-arid climate (Fig. 2). Mean annual precipitation is near $500 \mathrm{~mm}$, mean annual potential evapotranspiration is about $1332 \mathrm{~mm}$, and mean annual temperature is about $11.2^{\circ} \mathrm{C}$. Soil is classified as Calcic cambisols (FAO-UNESCO, 1988) with shallow depths $(10-30 \mathrm{~cm})$ and coarse texture (sand-28.7\%, silt-68.7\%, and clay-2.6\%, percent by volume), and the parent material is phyllite. Vegetation here is dominated by arid shrubs, such as Sophora viciifolia, Indigofera bungeana and Bauhinia faberi var. microphylla, and sparse grasses, such as Ajania breviloba, Sedum wenchuanense and Heteropogon contortus.

\subsection{Data collection}

Field experiments were carried out in August 2006 at three sites (Fig. 2) with different vegetation characteristics. Shidaguan, on the upper reaches of the core area, was dominated by short dry grasses and dwarf dry shrubs, on both north- and south-facing slopes. Within the central part, Feihongguan, vegetation consisted only of sparse dwarf dry shrubs on north-facing slopes and sparse grasses on southfacing slopes. Within the lower portion, Nanxin, some small trees occupied north-facing slopes, but only sparse shrubs were present on south-facing slopes. At each site, two transects were placed on opposite (i.e. south and north facing) slopes, oriented to make a ' $\mathrm{V}$ ' shape. 


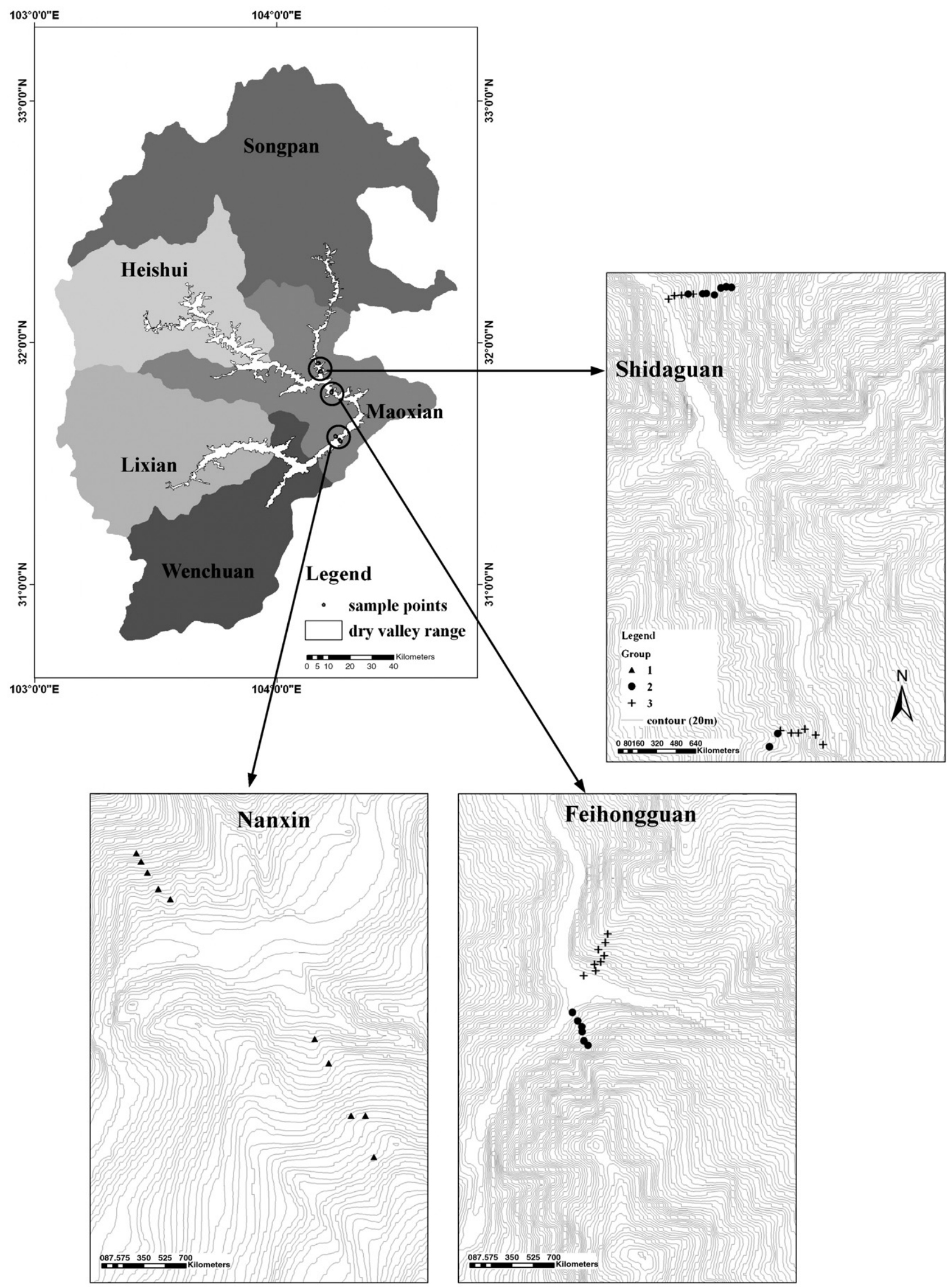

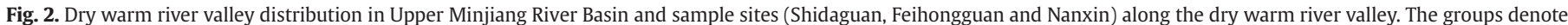
the classified three groups of sample points by Cluster Analysis according to the soil properties (refer to Materials and methods section). 
Sample points were selected along transects at about $20 \mathrm{~m}$ intervals in elevation. In total, 43 points were selected (Fig. 2). Normally, three replicate homogenous sample plots $(5 \times 5 \mathrm{~m})$ were set up in each point, but occasionally only one or two plots were feasible. More than three plots were sampled if the vegetation area (point) was large enough. In these plots, all shrub species were identified and measured for layer coverage (ShrubCov), total height (ShrubHei) and frequency. Within each sample plot, three replicate quadrates $(1 \times 1 \mathrm{~m})$ on the diagonal line were chosen, where herb species were identified and measured for layer coverage (HerbCov) and height (HerbHei), and species frequency. The litter coverage (LitterCov) was also recorded. Two plant diversity indices were calculated as follows:

1) Shannon-Wiener index (Denoted as ShrubDiv and HerbDiv respectively for shrub and herb layer)

$$
H=-\sum_{i=1}^{S}\left(p_{i}\right)\left(\ln p_{i}\right)
$$

Where:

\section{H Shannon-Wiener Diversity}

$S \quad$ total number of species in the sample

$p_{i} \quad$ proportion of all individuals in sample that belong to species $i$ $\ln p_{i} \quad$ natural $\log$ of $p_{i}$

2) Richness (Denoted as ShrubRic and HerbRic respectively for shrub and herb layer) is simply a count of the number of species present in a sample.

Knowing that soil water content (SWC) varies over time due to fluctuations in rainfall and plant water requirements in the summer season and the importance of keeping the sampling conditions similar, SWC was collected on sunny days within a 2-week period without rainfall. The sampling procedure was similar to that used by Ma et al. (2004) and Lu et al. (2006). Within each sample plot, the surface soil moisture $(0-15 \mathrm{~cm})$ was determined at nine points using a portable Time Domain Reflectometry (TDR). Also, five soil samples $(0-15 \mathrm{~cm})$ were collected for soil texture and chemical analyses using cores $(5 \mathrm{~cm}$ diameter) from five random soil profiles, air-dried, thoroughly mixed, and passed through a $2 \mathrm{~mm}$ sieve to remove gravel and debris. Soil clay content (Clay, $<2 \mu \mathrm{m}$ ) was measured by laser diffraction technique with Mastersizer2000 (Malvern Instruments Ltd, UK). The semimicroKjeldahl method was used to determine the total soil nitrogen (TN). Total phosphorus (TP) was determined colorimetrically after wet digestion with $\mathrm{H}_{2} \mathrm{SO}_{4}$ plus $\mathrm{HClO}_{4}$ (Parkinson and Allen, 1975). Available nitrogen (AN) was determined by the Cornfield method (alkaline hydrolysable nitrogen). Available potassium (AK) and available phosphorus (AP) were extracted with $3 \%\left(\mathrm{NH}_{4}\right)_{2} \mathrm{CO}_{3}$ solution. After filtering, the solution was measured by icp-aes (Editorial Committee, 1996). Soil organic carbon (SOC) was determined by the $\mathrm{K}_{2} \mathrm{Cr}_{2} \mathrm{O}_{7}$ titration method after digestion (Nelson and Sommers, 1975). Total potassium (TK) was determined by atomic absorption spectrometer (Editorial Committee, 1996). Soil pH was determined in 1:2.5 soil-water slurry. Electrolytic conductivity (Ec) was measured using a portable conductivity meter (Cole-Parmer Instrument Company, USA). To improve the precision of the results, three replicates were analyzed and averaged for each of the soil nutrient analyses.

The following topographic attributes for each sample plot were calculated from digital elevation model (DEM, $20 \mathrm{~m}$ ) using Arcgis 9.0:

1) Slope (SLP, degree)

2) Slope aspect (ASP) were converted using cosine function, range from -1 to 1 indicating from south to north

3) Topographic wetness index (TW), which ranges from a minimum of 0 for the most xeric conditions to a maximum of 60 for the most mesic conditions, was computed by summing the separate components that express the range of xeric to mesic conditions due to aspect, slope steepness, slope configuration, and slope position (see Parker, 1982 for details of the computation).We revised the original TW 0 to 60 scaling index (dryer to wetter) to a more compact index ranging from 0 to 28 (dryer to wetter). To great extent, it also reflects runoff redistribution controlled by topographic characteristics

4) Length slope factor (LSF) as defined by an algorithm derived from the unit power theory by Moore and Burch (1986), is a potential sediment transport index: LS $=(\text { Flow Accumulation } \times \text { Cell Size } / 22.13)^{0.4} \times($ sin $\mathrm{SLP} / 0.0896)^{1.3}$. Flow Accumulation here was calculated as the number of upstream cells draining to a target cell, using a single drainagedirection algorithm; Cell Size was $20 \mathrm{~m}$ in this paper.

5) Elevation (ELE, above sea level) and relative elevation (RelaELE, the elevation range between the sample plot and the valley bottom of each site)

\subsection{Data analysis}

To discern the complicated relationships between vegetation and soil and topography, a four-staged procedure was proposed in this study. The first stage was to classify three groups for soil properties reflecting different soil fertile level (using K-Means Cluster Analysis method), and then One-way analysis of variance (ANOVA) with Tukey method was employed to compare the difference for each variable among the three groups (at 0.05 level).

The principal component analysis (PCA) was applied at the second stage. This was first applied to the vegetation variables in order to define non-correlated vegetation characteristics after orthogonal rotation of the axes using the varimax method. Varimax rotation is the most common of the rotations that are available, and it can make each factor (principal component) only has a few variables with large loadings, which facilitates interpretation. PCA was performed using the correlation coefficient matrix, an approach less sensitive to

\section{Table 1}

Soil, topography and vegetation variables (Mean \pm Std. E.) of the three classified groups (Group1, Group2 and Group3)

\begin{tabular}{|c|c|c|c|c|c|}
\hline \multirow[t]{2}{*}{ Variables } & \multirow{2}{*}{$\frac{\text { Group1 }}{N=10}$} & \multirow{2}{*}{$\begin{array}{l}\text { Group2 } \\
N=15\end{array}$} & \multirow{2}{*}{$\begin{array}{l}\text { Group3 } \\
N=18\end{array}$} & \multirow[t]{2}{*}{$F$} & \multirow[t]{2}{*}{$p$} \\
\hline & & & & & \\
\hline $\begin{array}{l}\text { SWC (\%, volume } \\
\text { percent) }\end{array}$ & $12.2 \pm 1.4 a$ & $2.3 \pm 0.4 b$ & $0.8 \pm 0.1 \mathrm{c}$ & 83.7 & $<0.001$ \\
\hline Clay (\%) & $5.9 \pm 0.5 a$ & $2.8 \pm 0.2 b$ & $1.9 \pm 0.1 c$ & 79.16 & $<0.001$ \\
\hline $\mathrm{Ec}(\mu \mathrm{s} / \mathrm{cm})$ & $573.2 \pm 47.3 \mathrm{ab}$ & $660.7 \pm 77.3 a$ & $301.7 \pm 18.7 b$ & 14.64 & $<0.001$ \\
\hline $\mathrm{pH}$ & $7.9 \pm 0.1 \mathrm{ab}$ & $7.7 \pm 0.1 b$ & $8.0 \pm 0.1 \mathrm{a}$ & 3.99 & 0.026 \\
\hline SOC (\%) & $4.3 \pm 0.4 b$ & $6.3 \pm 0.6 a$ & $2.9 \pm 0.3 b$ & 16.9 & $<0.001$ \\
\hline $\mathrm{TN}(\mathrm{g} / \mathrm{kg})$ & $4.1 \pm 0.5 b$ & $6.9 \pm 0.7 a$ & $3.5 \pm 0.5 b$ & 9.64 & $<0.001$ \\
\hline AN (mg/kg) & $298.9 \pm 30.6 b$ & $465.9 \pm 32.6 a$ & $202.8 \pm 17.6 c$ & 28.43 & $<0.001$ \\
\hline $\mathrm{AP}(\mathrm{mg} / \mathrm{kg})$ & $11.5 \pm 2.2$ & $18.1 \pm 1.9$ & $13.6 \pm 2.1$ & 2.33 & 0.111 \\
\hline $\mathrm{TP}(\mathrm{g} / \mathrm{kg})$ & $0.9 \pm 0.1 \mathrm{ab}$ & $1.1 \pm 0.1 \mathrm{a}$ & $0.7 \pm 0.0 \mathrm{~b}$ & 4.28 & 0.021 \\
\hline $\mathrm{AK}(\mathrm{mg} / \mathrm{kg})$ & $580.8 \pm 53.2 a$ & $316.6 \pm 31.2 b$ & $181.8 \pm 14.8 \mathrm{c}$ & 38.93 & $<0.001$ \\
\hline $\mathrm{TK}(\mathrm{g} / \mathrm{kg})$ & $18.2 \pm 0.9 b$ & $21.8 \pm 0.9 b$ & $26.8 \pm 1.1 \mathrm{a}$ & 16.48 & $<0.001$ \\
\hline $\operatorname{ELE}(\mathrm{m})$ & $1845.8 \pm 56.8$ & $1944.7 \pm 45.4$ & $1834.0 \pm 26.9$ & 2.37 & 0.107 \\
\hline RelaELE (m) & $445.3 \pm 48.6 a$ & $237.5 \pm 32.9 b$ & $157.8 \pm 25.9 b$ & 16.61 & $<0.001$ \\
\hline SLP (degree) & $26.0 \pm 3.1 b$ & $37.7 \pm 2.5 a$ & $36.3 \pm 2.5 a$ & 4.59 & 0.016 \\
\hline ASP & $-0.1 \pm 0.3 \mathrm{ab}$ & $0.3 \pm 0.1 \mathrm{a}$ & $-0.4 \pm 0.1 b$ & 5.31 & 0.009 \\
\hline TW & $9.9 \pm 1.7$ & $9.8 \pm 0.6$ & $9.1 \pm 0.9$ & 0.19 & 0.829 \\
\hline LSF & $12.4 \pm 2.1$ & $14.5 \pm 1.1$ & $15.6 \pm 2.0$ & 0.72 & 0.495 \\
\hline ShrubCov (\%) & $62 \pm 5 a$ & $56 \pm 6 a$ & $38 \pm 2 b$ & 8.79 & 0.001 \\
\hline ShrubHei (cm) & $80 \pm 8 a b$ & $85 \pm 9 a$ & $55 \pm 4 b$ & 5.52 & 0.008 \\
\hline ShrubDiv & $1.8 \pm 0.2 \mathrm{a}$ & $1.6 \pm 0.1 \mathrm{ab}$ & $1.4 \pm 0.1 b$ & 4.87 & 0.013 \\
\hline ShrubRic & $8.8 \pm 1.0 \mathrm{a}$ & $5.8 \pm 0.3 b$ & $4.5 \pm 0.2 b$ & 16.49 & $<0.001$ \\
\hline HerbCov (\%) & $65 \pm 4$ & $63 \pm 4$ & $66 \pm 2$ & 0.24 & 0.789 \\
\hline HerbHei (cm) & $26 \pm 2$ & $31 \pm 2$ & $25 \pm 2$ & 2.51 & 0.094 \\
\hline HerbDiv & $1.1 \pm 0.1 \mathrm{a}$ & $1.1 \pm 0.0 \mathrm{a}$ & $0.9 \pm 0.1 b$ & 9.21 & 0.001 \\
\hline HerbRic & $4.4 \pm 0.4 a$ & $4.0 \pm 0.1 \mathrm{a}$ & $3.1 \pm 0.1 b$ & 10.24 & $<0.001$ \\
\hline LitterCov (\%) & $42 \pm 5 a$ & $27 \pm 6 a b$ & $21 \pm 3 b$ & 4.29 & 0.021 \\
\hline
\end{tabular}

Different letters (a, b, c) in the same row present significant $(p<0.05)$ difference between the groups.

Abbreviations refer to Materials and methods section. 
Table 2

The loadings of each group of variables (vegetation, soil and topography) on the first three significant PCs (eigenvalue $>1$ ) after varimax rotation of the axes

\begin{tabular}{|c|c|c|c|c|c|c|c|c|c|c|c|}
\hline Component & 1 & 2 & 3 & Component & 1 & 2 & 3 & Component & 1 & 2 & 3 \\
\hline Eigenvalues & 3.5 & 1.9 & 1.7 & Eigenvalues & 3.1 & 3.1 & 1.4 & Eigenvalues & 1.8 & 1.7 & 1.6 \\
\hline$\%$ of Variance & 38.4 & 21.6 & 18.4 & $\%$ of Variance & 28.1 & 28.0 & 13.2 & $\%$ of Variance & 30.3 & 27.8 & 27.0 \\
\hline Cumulative \% & 38.4 & 60.0 & 78.3 & Cumulative \% & 28.1 & 56.1 & 69.3 & Cumulative \% & 30.3 & 58.1 & 85.0 \\
\hline ShrubCov & 0.489 & -0.579 & 0.483 & $\mathrm{pH}$ & 0.012 & -0.101 & 0.882 & ElE & 0.281 & 0.046 & 0.875 \\
\hline ShrubHei & 0.203 & -0.602 & 0.601 & Ec & 0.341 & 0.666 & -0.154 & RelaELE & 0.020 & -0.212 & 0.893 \\
\hline ShrubDiv & 0.837 & 0.133 & 0.218 & SWC & 0.900 & -0.007 & 0.174 & SLP & 0.003 & 0.920 & -0.017 \\
\hline ShrubRic & 0.867 & 0.116 & 0.186 & Clay & 0.898 & -0.006 & -0.024 & ASP & 0.929 & 0.026 & 0.145 \\
\hline HerbCov & 0.045 & 0.888 & -0.044 & SOC & 0.165 & 0.798 & -0.331 & TW & 0.933 & 0.010 & 0.122 \\
\hline HerbHei & -0.174 & -0.132 & 0.861 & $\mathrm{TN}$ & 0.030 & 0.807 & -0.125 & LSF & 0.033 & 0.881 & -0.138 \\
\hline HerbDiv & 0.824 & -0.242 & -0.314 & AN & 0.168 & 0.661 & -0.527 & & & & \\
\hline HerbRic & 0.860 & -0.102 & -0.319 & $\mathrm{AP}$ & -0.195 & 0.542 & -0.022 & & & & \\
\hline \multirow[t]{3}{*}{ LitterCov } & 0.521 & 0.579 & -0.182 & $\mathrm{TP}$ & 0.127 & 0.749 & 0.328 & & & & \\
\hline & & & & AK & 0.834 & 0.122 & -0.014 & & & & \\
\hline & & & & $\mathrm{TK}$ & -0.742 & -0.184 & 0.320 & & & & \\
\hline
\end{tabular}

The bold figures in Table (above 0.55 ) present closely relationships between variables and the specific principal component.

extreme values. PCA was then applied to the soil and topographic variables in order to eliminate any redundancy among the variables. A variable was significantly correlated with a PC when the correlation (its loading value) with this component was at least 0.55. A PC was considered significant when its eigenvalue was at least 1 .

The third stage consisted in calculating the linear correlation coefficients between the factorial scores of PC extracted from vegetation, soil and topographic variables. This stage allows us to determine the environmental factors (PCs of the soil and topographic variables) that influence the vegetation characteristics. Since the simple correlation analysis (SCA) do not account for the interaction between variables of the same group, we also applied the canonical correlation analysis (CCA) method. The technique consists in finding several linear combinations of $\mathrm{X}$ variables and the same number of linear combinations of $Y$ variables in such two data sets. Linear combinations are the canonical variables, and the correlations between corresponding pairs of canonical variables are canonical correlations. Each of the pairs of canonical variables then represents an independent dimension in the relationship between the two sets of variables, and the importance of the canonical correlations decreases sequentially. In short, the maximization aspect of the technique concentrates a high-dimension relationship between two sets of variables into a few pairs of orthogonal canonical variables.

Important factors (PCs of soil and topography) correlated with vegetation characteristics were identified using SCA and CCA. To determine the specific variable impacting each index of vegetation composition and soil water content, we conducted multiple linear stepwise regression analysis at the last stage.

All analyses were conducted in SPSS 10.0 software except the CCA in DPS 7.05.

Table 3

Correlation coefficients between different PCs

\begin{tabular}{llllllllll}
\hline & PCV1 & PCV2 & PCV3 & PCS1 & PCS2 & PCS3 & PCT1 & PCT2 & PCT3 \\
\hline PCV1 & 1 & & & & & & & & \\
PCV2 & 0 & 1 & & & & & & & \\
PCV3 & 0 & 0 & 1 & & & & & & \\
PCS1 & $\mathbf{0 . 6 7 * *}$ & 0.07 & 0.21 & 1 & & & & & \\
PCS2 & 0.29 & 0.05 & $\mathbf{0 . 3 3 *}$ & 0 & 1 & & & & \\
PCS3 & -0.13 & 0.1 & -0.09 & 0 & 0 & 1 & & & \\
PCT1 & $\mathbf{0 . 4 8 * *}$ & 0.13 & 0.25 & 0.16 & $\mathbf{0 . 3 4 *}$ & -0.01 & 1 & & \\
PCT2 & -0.27 & -0.13 & 0.12 & -0.3 & 0.17 & -0.1 & 0 & 1 & \\
PCT3 & $\mathbf{0 . 3 9 * *}$ & -0.28 & 0.06 & 0.29 & 0.05 & $\mathbf{- 0 . 3 4 *}$ & 0 & 0 & 1 \\
\hline
\end{tabular}

${ }^{*} p<0.05 ; * * p<0.01$.

PCV1, PCV2 and PCV3, respectively denote the first, second and third principal component for vegetation; PCS1, PCS2 and PCS3, respectively denote the first, second and third principal component for soil; PCT1, PCT2 and PCT3, respectively denote the first, second and third principal component for topography.

\section{Results}

3.1. Topography and vegetation features classified by soil fertility level using $C A$

Among soil properties, SWC, Clay, AN and AK were statistically different between any two groups, and thus played important roles in the classification (Table 1). SWC and Clay were highest for group1, and followed respectively by Group2 and Group3. For chemical nutrients (SOC, TN, AN, TP), it was highest for Group2, and followed respectively by Group 1 and Group3. For topographic characteristics, Group1 had the highest relative elevation (RelaELE) and the least slope steepness. For vegetation characteristics, the first two groups had relatively higher values than the third one. Among the plant variables, all plant diversity indices were slightly higher for Group1 than that for Group2, while plant height was opposite trend. In general, the first two groups had higher soil quality, more complex plant composition and higher plant cover and height, and the two groups were mainly located on the topographic position with lower solar incident radiation (north-facing slope), runoff (high TW) and soil erosion potential (low LSF).

\subsection{PCA of vegetation, soil and topographic factors}

Table 2 shows the loadings of each group of variables (vegetation, soil and topography) on the first three significant PCs (eigenvalue $>1$ ) after varimax rotation of the axes. For vegetation, these three PCs explained about $78 \%$ of the total variance, and the first two accounted for almost $60 \%$. Loading values revealed that each characteristic was associated with a specific PC (with a value of $>0.55$ ). The first component was positively associated with plant diversity indices (ShrubRic, HerbRic, ShrubDiv and HerbDiv). The second was associated with HerbCov, ShrubHei and to a lesser extent, with ShrubCov and LitterCov. The third PC was positively associated with plant height (ShrubHei and HerbHei). For soil, the three components explained about $69 \%$ of the total variance, of which above half was accounted for by the first two PCs. The first component was positively associated with SWC, Clay and AK, while negatively with TK. The second was positively associated with soil nutrients (TN, SOC, TP and AN) and Ec. The third PC was positively associated with pH. For topography, the first three PCs could explain $85 \%$ of the total variance, of which about

Table 4

Canonical correlation analysis statistics

\begin{tabular}{lllcrl}
\hline No. & Correlation coefficient & Wilk's & Chi-Square & $d f$ & $p$ \\
\hline 1 & 0.8914 & 0.1652 & 66.6114 & 18 & 0.0001 \\
2 & 0.3546 & 0.8045 & 8.0491 & 10 & 0.6240 \\
3 & 0.2825 & 0.9202 & 3.0762 & 4 & 0.5452
\end{tabular}


Table 5

Correlations between the first three PCA components of the vegetation variables and the first three canonical roots

\begin{tabular}{lllllll}
\hline & U1 & U2 & U3 & V1 & V2 & V3 \\
\hline PCV1 & $\mathbf{0 . 9 1 8 6}$ & -0.2086 & -0.3357 & $\mathbf{0 . 8 1 8 8}$ & -0.074 & -0.0948 \\
PCV2 & 0.0743 & $\mathbf{0 . 9 2 5 4}$ & -0.3716 & 0.0662 & 0.3282 & -0.105 \\
PCV3 & 0.3882 & 0.3164 & $\mathbf{0 . 8 6 5 5}$ & 0.3461 & 0.1122 & 0.2445 \\
\hline
\end{tabular}

Higher figures represent higher correlations and the bold figures of $>0.55$ are considered significant correlations.

$58 \%$ was accounted for by the first two components. The first PC was positively associated with TW and ASP representing runoff redistribution and solar incident radiation. The second was positively associated with SLP and LSF representing slope steepness and soil erosion potential. The third was positively with RelaELE and ELE representing the elevation.

\subsection{Analysis of correlations between vegetation, soil and topographic factors}

Table 3 shows the simple correlation values calculated between vegetation, soil and topographic characteristics represented by the PCs extracted from the original variables. It showed that the PCV1, namely plant diversity, was positively associated with the PCS1 (SWC, Clay, AK and TK), the PCT1 (TW and ASP) and the PCT3 (elevation), while the PCV3 (plant height) only positively associated with the PCS2 (soil nutrients). In addition, the PCS2 (soil nutrients) was positively associated with the PCT1 (TW and ASP), while the PCS3 (pH) negatively associated with PCT3 (elevation).

The fact that simple correlation analysis does not take into account potential links between independent variables may lead to redundancies, which make it difficult to pin down the exact effect of each factor on vegetation characteristics. CCA gets around this problem by taking into account the links that exist between variables of the same group and between two groups of variables. Table 4 shows the three canonical correlation coefficients derived from the vegetation variables and, the soil and topographic ones. Coefficient values thus obtained are greater than 0.80 , which indicated a strong link between the vegetation variables and the soil and topographic ones, already suggested by simple correlation analysis (Table 3). Table 5 reveals that the first canonical variable was represented by PCV1 (plant diversity), the second canonical variable was related to the PCV2 (plant cover), and the third to the PCV3 (plant height). Concerning soil and topographic factors (Table 6), the first canonical variable was correlated with the PCS1 (SWC, Clay, AK and TK), and the PCT1 (TW and ASP). The second canonical correlation was correlated with the PCS2 (soil nutrients) and the PCT3 (elevation). The third canonical variable was correlated with the PCT2 (SLP and LSF, reflecting slope steepness and soil erosion potential). The fact only the first canonical correlation coefficient was statistically significant (Table 4), indicated the relationships between PCV1, PCS1, and PCT1 were more closely correlated with each other.

Results from the two correlation methods (simple correlation and CCA) are in agreement. Indeed, CCA confirmed the influence of the soil

\section{Table 6}

Correlations between the first three PCA components of soil and topography variables, and the first three canonical roots

\begin{tabular}{lrrrrrr}
\hline & \multicolumn{1}{l}{ V1 } & \multicolumn{1}{l}{ V2 } & \multicolumn{1}{l}{ V3 } & \multicolumn{1}{l}{ U1 } & \multicolumn{1}{l}{ U2 } & \multicolumn{1}{l}{ U3 } \\
\hline PCS1 & $\mathbf{0 . 7 8 4 8}$ & -0.0312 & -0.2253 & $\mathbf{0 . 6 9 9 6}$ & -0.0111 & -0.0636 \\
PCS2 & 0.4404 & 0.2533 & $\mathbf{0 . 5 9 4 3}$ & 0.3926 & 0.0898 & 0.1679 \\
PCS3 & -0.1647 & 0.2491 & -0.2523 & -0.1468 & 0.0883 & -0.0713 \\
PCT1 & $\mathbf{0 . 6 1 4 2}$ & 0.2677 & 0.0277 & 0.5475 & 0.0949 & 0.0078 \\
PCT2 & -0.2369 & -0.0672 & $\mathbf{0 . 8 6 2 1}$ & -0.2111 & -0.0238 & 0.2435 \\
PCT3 & 0.4021 & $\mathbf{- 0 . 9 0 6 9}$ & 0.0848 & 0.3584 & -0.3216 & 0.024 \\
\hline
\end{tabular}

Higher figures represent higher correlations and the bold figures of $>0.55$ are considered as significant correlations.
Table 7

Multiple linear stepwise regression analysis for plant diversity indices

\begin{tabular}{lllll}
\hline Dependent variable & Model & Equation & $R^{2}$ & \multicolumn{1}{l}{$p$} \\
\hline ShrubDiv & 1 & ShrubDiv $=0.952+0.061 \mathrm{TW}$ & 0.364 & $<0.001$ \\
& 2 & ShrubDiv=0.922+0.052TW+0.030SWC & 0.519 & $<0.001$ \\
ShrubRic & 1 & ShrubRic $=4.51+0.361$ SWC & 0.566 & $<0.001$ \\
& 2 & ShrubRic $=4.772+0.316$ SWC+1.245ASP & 0.687 & $<0.001$ \\
HerDiv & 1 & HerDiv $=0.915+0.022$ SWC & 0.238 & 0.001 \\
HerbRic & 1 & HerbRic $=3.229+0.115$ SWC & 0.374 & $<0.001$ \\
& 2 & HerbRic $=3.332+0.097$ SWC+0.486ASP & 0.495 & $<0.001$ \\
\hline
\end{tabular}

Independent variables: SWC, Clay, TW, ASP, RelaELE and ELE.

properties such as SWC, Clay, AK and TK and the topographic factors such as TW and ASP on the plant diversity.

\subsection{Factors directly affecting plant diversity and soil water content}

To determine the specific factors affecting plant diversity, we conducted the multiple linear stepwise regression analysis for each index of plant diversity (dependent variables) to potential affecting factors. Because the PCV1 was positively associated with PCS1, PCT1 and PCT3 (simple correlation analysis), the potential affecting factors (independent variables) included SWC, Clay, TW, ASP, ELE and RelaELE. The results were listed in Table 7. For shrub diversity (ShrubDiv), TW entered both two regression models, and SWC entered the second model. For shrub richness (ShrubRich), both two models had the SWC factor. ASP also entered the second model. For herb diversity (HerbDiv), only SWC entered the model. For herb richness (HerbRich), SWC entered both two models, and ASP also entered the second model. These results thus confirmed soil water content (SWC) was the most important factor affecting plant diversity.

Because of the importance of the soil water content, we conducted multiple linear stepwise regression analysis to determine the factor or factors directly affecting soil water content. The independent variables included soil clay content and all topographic variables (ELE, RelaELE, LSF, SLP, TW, ASP). Soil clay content was the most important determinant factor that alone could explain about $70 \%$ of the total variance (SWC $=-3.527+2.411$ Clay, $\left.R^{2}=0.701, p<0.001\right)$.

\section{Discussion and conclusions}

It is a great challenge to clarify the complicated relationships between vegetation and soil and topography. As described by Solon et al. (2007), vegetation is an easily discernible, recognizable and labile component of the natural environment that reacts to changes in other components. One of the most important components influencing vegetation is the soil, and both vegetation and soil are influenced by topography. Good soil environments can provide plants with enough nutrients and available water, and topographic characteristics (e.g., elevation and slope aspect) are closely associated with local climate (e.g. precipitation, evaporation and solar incident radiation) that greatly impacts plants (Davies et al., 2007). Topographic characteristics (TW and LSF) can also regulate seed, water and materials redistribution, thereby impacting plants distribution pattern (Parker, 1982; Canton et al., 2004; Fu et al., 2004). Most research was concerned on the relationships between any two components, but few comprehensively on the relationships between vegetation and soil and topography. For example, Maestre et al. (2003) and Lu et al. (2006) considered the relationship between vegetation and soil, and Pinder et al. (1997) and Canton et al. (2004) considered vegetation and topography. Even if some research considered vegetation and soil and topography (Solon et al., 2007; Pueyo et al., 2007), they only aimed to find the factors impacting vegetation but not directly for ecosystem restoration practices. As for our study, the aim is clearly directed toward ecosystem restoration and management, i.e. finding the key factors for restoration and improvement of vegetation and soil, thus we proposed the four-staged procedure to discern the 
relationships between vegetation and soil and topography step by step and finally got the valuable information.

According to cluster analysis (CA) shown in Table 1, high vegetation community complexity, and plant cover and height were closely correlated with high soil quality and favorable topographic positions with lower solar incident radiation, runoff and soil erosion potential. Among all the soil properties, SWC, Clay, AN and AK were statistically different between any two groups, and they were the most important factors reflecting the soil quality levels in this area. By principal component analysis (PCA) shown in Table 2, each group of variables (vegetation, soil and topography) were combined into three PCs, and redundancy among variables of each group was reduced. Simple correlation analysis (Table 3 ) showed plant diversity (PCV1) was mainly affected by the factors related to soil physical properties (PCS1), and some topographic factors (PCT1, PCT3), while PCV3 (plant height) was closely related with PCS2 (soil nutrients). The study by Ye et al. (2005) in this area also documented soil nutrients positively affected aboveground biomass. Canonical correlation analysis (CCA, shown in Tables 5 and 6) confirmed plant diversity was mainly affected by soil physical properties (PCS1) and some topographic factors (PCT1). Regression analysis (Table 7) further affirmed soil water content was the most important factor affecting plant diversity. The study in this area by Lu et al. (2006) also emphasized the importance of soil water content in explaining plant variations. Enough range in available soil water can support much more types of plants, thereby increasing the complexity in vegetation composition. Soil water content can also impact many other biological and chemical processes, and thereby impact vegetation. For example, Solon et al. (2007) documented the number of species varied according to the joint patterns of soil acidity and soil water content. Another significant result of this study by regression analysis was that soil clay strongly influenced soil water content $\left(S W C=-3.527+2.411\right.$ Clay, $R^{2}=0.701$, $p<0.001$ ), and thereby influenced plant diversity (CA in Table 1, SCA in Table 3 and CCA in Tables 5 and 6). Davies et al. (2007) also documented positive association of soil clay content with plant species composition in a semi-arid environment. In such arid environments, soil was coarse-textured (He et al., 2004) leading to the weak capacity in holding soil water. Maestre et al. (2003) also documented the fine-textured soil as compared with the coarse-textured had higher soil water storage capacity, thereby facilitating seedling establishment and survival. This also partly explained the higher plant diversity of the shrubs than that of the herbs (Table 1). As compared with herbs, shrubs with relatively extensive roots could absorb water resources at different depths (Lu et al., 2006; Davies et al., 2007). However, up to now, most of the existing research in this area was only on soil nutrients (Wang et al., 2003), or the response of plant physiological characteristics to environmental stress (Li et al., 2005, 2006b). Even if there existed some soil water related studies (He et al., 2004; Ma et al., 2004), few examined the effects of soil texture on soil water content. Yet, it is just the most critical requirements for ecosystem restoration and management. Under such coarse-textured soil environments, knowing the spatial distribution of soil texture and its controlling mechanisms would be useful in selecting sites for plantation. In addition, as shown by our study (Tables 3, 5 and 6), some topographic characteristics (e.g., TW and ASP), which in fact affect local microenvironments, also affected vegetation composition. Much research was in agreement with our results (Pinder et al., 1997; Canton et al., 2004; Pueyo et al., 2007). Therefore, we should also make full use of microtopography to select potential sites for seeding.

Although many similar results from other studies were cited to support ours above, there still existed some different aspects between our and other studies. For example, Davies et al. (2007) documented slope was the only non-soil factor that was correlated with plant species composition, while TW and ASP were more important than slope (SLP) in our study. Soil organic carbon (SOC) seemed less important in impacting species composition in our study than in others (Fu et al., 2004;
Davies et al., 2007; Solon et al., 2007). However, it is very difficult to really discern the difference in the results from different studies, because the vegetation-soil-topography relationship is very complicated per se, the aims of different studies and associated measures were very different and, the local conditions also varied from one study to another.

Ecosystem restoration and management should consider both vegetation and soil. Co-evolution of vegetation and soil could lead to strong resilience of ecosystem. In these processes, vegetation plays active roles (Abadin et al., 2002; Bonet, 2004). On the one hand, vegetation could directly improve soil environments such as by enhancing nutrient availability or nutrient capture (Hobbie, 1992; Wilson and Agnew, 1992). On the other hand, they also could protect soil quality by reducing soil material loss (Bochet et al., 1999). Conversely, the improved soil environments could facilitate plants recruits' establishment (Ludwig and Tongway, 1996; Arbelo et al., 2006). Thus it forms a feedback circle, which could drive current ecosystem up into a higher level of succession. This is just the important theory or framework to direct the practice of ecosystem restoration and management, that is, it is difficult to directly restore original species in the degraded dry lands, several steps following natural succession sequence would be necessary. We agree with the suggestions by Zhou et al. (2008) that drought-resistant shrubs, and pioneering species should have priority, and then zonal species are introduced once the environment has been sufficiently modified by the pioneer and early successional species. In addition, land degradation is not only an ecological, but also an economic and social problem, some relevant conservation polices are needed to reduce human disturbance on these lands (Ma et al., 2004). These polices could include forbidding forest clear-cutting, returning farmland in unsuitable places to natural vegetation, and preventing other activities that might further cause vegetation damage and soil and water loss.

In this study, we proposed a four-staged procedure by combining several multivariate statistical approaches in order to discern the complicated relationships between vegetation and soil and topography, which would also be a powerful tool for other areas. Following the four-staged procedure, the importance of soil water content in influencing vegetation composition, and the importance of soil texture in affecting soil water content were figured out. In order to restore the degraded area, we should consider the co-evolution of both vegetation and soil, and natural succession sequence should also be followed. Some relevant conservation polices are also needed to reduce human disturbance on ecosystem.

\section{Acknowledgements}

This study was supported by the National Natural Science Foundation of China (No. 40571005 and No. 40621061) to Bo-Jie Fu, and partly supported by the Project of Chinese Academy of Sciences (No. KZCX2XB2-02-31) to Ke-Ming Ma. We thank Min-Sheng Ye, Hui Yin, Liang Ge, Xiao-Peng Zheng from Beijing Forestry University and Jian-Yun Zhou from Northwest Sci-Tech University of Agriculture and Forestry for their help in field investigation. We thank Dr. John Gerrard from University of Birmingham, UK and the anonymous reviewer for many valuable comments on the earlier versions of the manuscript. We acknowledge Maoxian Mountain Ecosystem Research Station, Chengdu Institute of Biology, CAS for their supports in laboratory facilities.

\section{References}

Abadin, J., Gonzalez-Prieto, S.J., Sarmiento, L., Villar, M.C., Carballas, T., 2002 Successional dynamics of soil characteristics in a long fallow agricultural system of the high tropical Andes. Soil Biology and Biochemistry 34, 1739-1748.

Arbelo, C.D., Rodriguez-Rodriguez, A., Guerra, J.A., Mora, J.L. Notario, J.S., Fuentes, F, 2006. Soil degradation processes and plant colonization in abandoned terraced fields overlying pumice tuffs. Land Degradation and Development 17, 571-588.

Bochet, E., Rubio, J.L., Poesen, J., 1999. Modified topsoil islands within patchy Mediterranean vegetation in SE Spain. Catena 38, 23-44

Bonet, A., 2004. Secondary succession of semi-arid Mediterranean old-fields in southeastern Spain: insights for conservation and restoration of degraded lands. Journal of Arid Environments 56, 213-233. 
Canton, Y., Del Barrio, G., Sole-Benet, A., Lazaro, R., 2004. Topographic controls on the spatial distribution of ground cover in the Tabernas badlands of SE Spain. Catena 55 341-365.

Davies, K.W., Bates, J.D., Miller, R.F., 2007. Environmental and vegetation relationships of the Artemisia tridentate Spp. Wyomingensis alliance. Journal of Arid Environments $70,478-494$

Editorial Committee, 1996. Soil Physical and Chemical Analysis and Description of Soil Profiles. Standards Press of China, Beijing. (in Chinese with English abstract).

FAO-UNESCO, 1988. Soil Map of the World, Revised Legend. World Soil Resources Report, vol. 60. FAO, Rome.

Fu, B.J., Liu, S.L., Ma, K.M., Zhu, Y.G., 2004. Relationships between soil characteristics, topography and plant diversity in a heterogeneous deciduous broad-leaved forest near Beijing, China. Plant and Soil 261, 47-54.

He, Q., He, Y., Bao, W., 2004. Dynamics of soil water contents on south-facing slope of dry valley area in the upper reaches of the Minjiang River. Chinese Journal of Applied and Environmental Biology 10 (1), 068-074 (in Chinese with English abstract).

Hobbie, S., 1992. Effects of plant species on nutrient cycling. Trends in Ecology and Evolution 7, 336-339.

Li, F., Bao, W., Liu, J., 2005. Leaf characteristics and their relationship of Cotinus coggygria in arid river valley located in the upper reaches of Minjiang River with environmental factors depending on its altitude gradients. Acta Botanica Boreali-Occidentalia Sinica 25 (11), 2277-2284 (in Chinese with English abstract).

Li, A., Wang, A., Liang, S., Zhou, W., 2006a. Eco-environmental vulnerability evaluation in mountainous region using remote sensing and GIS-a case study in the upper reaches of Minjiang River, China. Ecological Modeling 192, 175-187.

Li, F., Bao, W., Liu, J., Wu, N., 2006b. Eco-anatomical characteristics of Sophoral davidi Leaves along an elevation gradient in upper Minjiang River dry valley. Chinese Journal of Applied Ecology 17 (1), 5-10 (in Chinese with English abstract).

Lu, T., Ma, K.M., Zhang, W.H., Fu, B.J., 2006. Differential responses of shrubs and herbs present at the Upper Minjiang River basin (Tibetan Plateau) to several soil variables. Journal of Arid Environments 67, 373-390.

Ludwig, J.A., Tongway, D.J., 1996. Rehabilitation of semiarid landscapes in Australia. II. Restoring vegetation patches. Restoration Ecology 4, 398-406.

Ma, K.M., Fu, B.J., Liu, S.L., Guan, W.B., Liu, G.H., Lv, Y.H., Anand, M., 2004. Multiple-scale soil moisture distribution and its implications for ecosystem restoration in an arid river valley, China. Land Degradation and Development 15, 75-85.

Maestre, F.T., Cortina, J., Bautista, S., Bellot, J., Vallejo, R., 2003. Small-scale environmental heterogeneity and spatiotemporal dynamics of seedling establishment in a semiarid degraded ecosystem. Ecosystems 6, 630-643.
Moore, I.D., Burch, G.J., 1986. Physical basis of the length-slope factor in the universal soil loss equation. Soil Science Society of America Journal 50, 1294-1298.

Nelson, D.W., Sommers, L.E., 1975. A rapid and accurate method for estimating organic carbon in soil. Proceedings of the Indiana Academy of Science 84, 456-462.

Parker, A.J., 1982. The topographic relative moisture index: an approach to soil moisture assessment in mountain terrain. Physical Geography 3, 160-168.

Parkinson, J.A., Allen, S.E., 1975. A wet oxidation procedure suitable for determination for nitrogen and mineral nutrients in biological material. Communications in Soil Science and Plant Analysis 6,1-11.

Pinder III, J.E., Kroh, G.C., White, J.D., Basham May, A.M., 1997. The relationship between vegetation type and topography in Lassen Volcanic National Park. Plant Ecology 131, 17-29.

Pueyo, Y., Alados, C.L., Maestro, M., Komac, B., 2007. Gypsophile vegetation patterns under a range of soil properties induced by topographical position. Plant Ecology 189, 301-311.

Schweinfurth, U., 1992. Mapping mountains: vegetation in the Himalaya. GeoJournal, $27,73-83$.

Solon, J., Degorski, M., Roo-Zielinska, E., 2007. Vegetation response to a topographicalsoil gradient. Catena 71, 309-320.

Wang, C., Bao, W., Chen, J., Sun, H., Xie, J., 2003. Profile characteristics and nutrients of dry cinnamon soils in dry valley of the upper Mijing River. Chinese Journal of Applied and Environmental Biology 9, 230-234 (in Chinese with English abstract).

Wangda, P., Ohsawa, M., 2006a. Gradational forest change along the climatically dry valley slopes of Bhutan in the midst of humid eastern Himalaya. Plant Ecology 186, 109-128.

Wangda, P., Ohsawa, M., 2006b. Structure and regeneration dynamics of dominant tree species along altitudinal gradient in a dry valley slopes of the Bhutan Himalaya. Forest Ecology and Management 230, 136-150.

Wilson, J.W., Agnew, O.D.Q. 1992. Positive-feedback switches in plant communities. Advances in Ecological Research 20, 265-336.

Yan, H., Bi, H., Li, R., Eldridge, R., Wu, Z., Li, Y., Simpson, J., 2006. Assessing climatic suitability of Pinus radiata (D. Don) for summer rainfall environment of southwest China. Forest Ecology and Management 234, 199-208.

Ye, M., Guan, W., Bai, Z., Ma, K., Liu, G., Wang, X., 2005. Ecological gradient of plant community in the dry valley of Minjiang River. Science of Soil and Water Conservation 3, 70-75 (in Chinese with English abstract).

Zhou, P., Luukkanen, O., Tokola, T., Nieminen, J., 2008. Vegetation dynamics and forest landscape restoration in the Upper Min River Watershed, Sichuan, China. Restoration Ecology 16, 348-358. 